\title{
Oral and dental manifestations of celiac disease in children: a case-control study
}

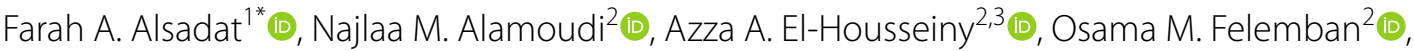 \\ Faisal M. Dardeer ${ }^{2}$ (1) and Omar I. Saadah ${ }^{4,5}$
}

\begin{abstract}
Background: Celiac disease (CD) is an immune-mediated enteropathy. CD may also involve complications with the oral cavity, which can result in various dental and oral pathologies. There are currently a limited number of studies on the oral manifestation of CD. This study aims to compare the oral manifestations of children with CD against healthy controls in Saudi Arabia.
\end{abstract}

Materials and methods: This study includes 208 children aged 6-14 years, distributed equally into CD patients and healthy controls. A parent completed and validated the interview questionnaire, which included the child's personal information and medical history. A dental examination was undertaken to measure possible recurrent aphthous stomatitis (RAS), dental enamel defects (DEDs), dental caries experience, and dental malocclusion. Data were analyzed using descriptive statistics and bivariate and multivariate analysis.

Results: Two hundred and eight participants were included (104 CD patients and 104 controls). The mean age for CD patients was $10.67 \pm 2.39$ years and $10.69 \pm 2.36$ for the healthy controls. CD children had more RAS than controls $(42.3 \%$ vs. $15.4 \%, P<0.001)(\mathrm{OR}=4.03,95 \% \mathrm{Cl}=2.09-7.81)$ and more $\mathrm{DEDs}$ than healthy controls $(70.2 \%$ vs. $34.6 \%$, $P<0.001)(\mathrm{OR}=4.45,95 \% \mathrm{Cl}=2.48-7.97)$. No significant difference was found in the frequency of malocclusion between cases and controls.

Conclusion: Saudi Arabian children with CD had a greater number of clinical findings of RAS and DEDs than healthy controls. Pediatric dentists should consider the possibility of CD in child patients presenting with RAS or DEDs.

Keywords: Celiac disease, Children, Dental enamel defect, Dental caries, And aphthous ulcer

\section{Introduction}

Celiac disease $(C D)$ is an immune related enteropathy in which small intestinal mucosal damage occurs in response to dietary gluten and other environmental triggers in individuals with genetic susceptibility; in particular, individuals carrying the HLA class II DQ2 and DQ8 haplotypes are at greatest risk [1].

The possible clinical presentations of CD can be categorized into intestinal and extraintestinal manifestations.

\footnotetext{
*Correspondence: falsadat@moh.gov.sa

1 Dental Department, Jubail General Hospital, Ministry of Health, P.O.

Box 1275, Al Jubail 31951, Saudi Arabia

Full list of author information is available at the end of the article
}

The classical intestinal manifestations include diarrhea, abdominal pain, abdominal distension, poor weight gain, and malnutrition [2]. The non-classical (extraintestinal) manifestations include short stature, osteopenia, osteoporosis, arthritis, dermatitis herpetiformis, and a number of other autoimmune diseases [3]. Oral manifestations have also been described by patients with $\mathrm{CD}[4,5]$. Various oral conditions have been reported in the literature, including recurrent aphthous stomatitis (RAS), dental enamel defects (DEDs), and delayed dental maturity [4, 6-9].

RAS is usually described as an oval or rounded painful lesions, with well-defined margins that are surrounded by 
a reddish base. It can affect all pediatric age groups, and mostly involves the labial mucosa or the lateral surface of the tongue [10]. RAS has been shown to be a risk indicator for CD [11]. DEDs are defects in the quantity or quality of enamel that could involve primary or permanent dentitions. DEDs may be the only clinical sign of asymptomatic non-classical CD [3]. DEDs tend to be symmetrical on similar teeth, mostly upper and lower incisors and molars that erupt simultaneously [11, 12]. Dental caries was reported in many studies in connection with CD. However, some studies have reported inconsistent and contradictory results regarding dental caries. Some studies have reported higher prevalence in CD children than matched controls [13]. Others report a lower prevalence of dental caries in CD children than healthy controls [12, 14]. Yet some investigators have found a lack of association between dental caries and $\mathrm{CD}[7,10,11]$.

In general, understanding of $\mathrm{CD}$ among many health care professionals, especially dentists, is minimal, so delayed diagnosis of $\mathrm{CD}$ is not unusual [15]. To the best of the authors' knowledge, there is currently no detailed and comprehensive study that examines oral features in children with $\mathrm{CD}$, including soft and hard tissues, dental caries, and orthodontic needs. Thus, this study aims to assess the oral health status of children with $C D$ with respect to RAS, DEDs, dental caries, and malocclusion in comparison with healthy controls.

\section{Materials and methods}

\section{Study design and sample size calculation}

This is a case-control study based on the Strengthening the Reporting of Observational Studies in Epidemiology (STROBE) [16] guidelines for reporting case-control studies. Data were collected between September 2017 and February 2020.

The sample size was calculated based on a previous study [13] using the outcome variable type I DEDs. Based on the study, the odds ratio of developing DED among CD subjects was estimated to be 3.21 compared to controls and was used for determining the total sample size, using power $80 \%$ and alpha risk $5 \%$, which was found to be 200 participants (100 patients and 100 healthy controls).

The inclusion criteria were the following for the patient group: children aged 6-14 years with biopsy-proven clinical diagnosis of $\mathrm{CD}$ based on the European Society for Pediatric Gastroenterology, Hepatology, and Nutrition (ESPGHAN) criteria [1]. For the control group the inclusion criteria were as follows: healthy children with no chronic illnesses. The exclusion criteria involved children with $C D$ that were treated with corticosteroids, had mental or physical disabilities, or congenital or chromosomal abnormalities. Participants with excessive intake of fluoride or tetracycline or with clinically manifest dental fluorosis were also excluded, as were children undergoing orthodontic treatment.

\section{Data collection and clinical assessment}

Patients were recruited in the pediatric gastroenterology clinic at King Abdulaziz University Hospital (KAUH). One hundred forty-nine contact numbers from the list of CD patients provided by the GI department were contacted; 104 subjects responded and agreed to participate (response rate was 69.8\%). In order to select a control group, each $\mathrm{CD}$ subject was given two invitation letters of enrolment to distribute randomly to two classmates. A total of 208 invitation letters were provided for the CD children (the response rate was 50\%). If parents approved their child's participation, a phone contact was carried out to make sure that the participants were healthy. Parents were asked to bring their child to the Pediatric Dentistry Clinics in King Abdulaziz University Dental Hospital (KAUDH). The child and parents were taken to the dental clinic, where parents were asked to complete a validated parent questionnaire. This step was followed by a clinical examination of the child. The dental exam concerned RAS and DEDs using Aine's classification system [17]. Caries experience using the decayed, missed, and filled teeth index ( $\mathrm{dmft}$ index for primary teeth and DMFT index for permanent teeth) was carried out according to WHO criteria [18]. Oral consequences related to advanced stages of untreated caries were measured using the pulp, ulceration, fistula, or abscess index (PUFA for permenant teeth/pufa for primary teeth) [19]. Malocclusion was assessed using the Dental Aesthetic Index (DAI) [20]. The clinical examinations were performed by a single trained calibrated examiner (kappa values for intra examiner reliabilities of $\mathrm{DMFT}=0.87$, $\mathrm{dmft}=0.85$, PUFA $=0.93$, pufa $=0.92, \mathrm{DED}=0.82$, and $\mathrm{DAI}=0.93$ ). The parent questionnaire was formulated to assess the general health status of each child. It was written in Arabic and divided into two parts. The first part comprised information regarding the child's sociodemographic data, general medical history, medications, and specific questions concerning the diagnosis and symptoms of CD. The second part concerned knowledge of the child's dental history, dietary habits, brushing habits, and specific questions related to water sources.

\section{Validation and reliability of the parent questionnaire}

The parent questionnaire was validated following its development. The validity was tested using content validity. It was given to a group of five medical and dental experts for the assessment of each item, based on specific criteria. Each item was given a score, and then a total average score was determined by dividing 
each count by the total number of experts. The content validity index for items (I-CVI) was calculated; any item with a score $<0.78$ was modified in terms of structure or language. Following this, the content validity index for the whole scale (S-CVI) was calculated [21]. The mean I-CVI score was 0.96 . The following content validity indices for S-CVI were obtained: relevance $=0.96$, clarity $=0.97$, simplicity $=0.98$, and ambiguity $=0.98$.

In order to test the reliability of the parent questionnaire, 20 parents of children attending KAUH not included in the study were interviewed (in the Arabic language). The interview was repeated two weeks later for test-retest reliability; the test illustrated high reliability, with an intraclass correlation (ICC) of 0.82 .

\section{Statistical analysis}

All data were revised for completeness and logical consistency, then inserted into the Statistical Package for the Social Sciences (SPSS, Inc., Chicago, I1, USA) program, version 21, for analysis. Data entry was checked twice, then checking for duplicates was performed by SPSS, followed by examining each numerical variable for outliers using dot plot, and outliers were verified. Descriptive statistics were used to examine sample characteristics; continuous variables were summarized as means and standard deviations; and counts and percentages were used to categorical variables. To explore the association between $\mathrm{CD}$ and the primary outcomes (i.e., DMFT/dmft, PUFA/pufa, RAS, DEDs, and malocclusion), bivariate analyses were conducted with chisquared tests, Fisher's exact tests, independent $t$-tests, or analysis of variance (ANOVA) tests. Post-hoc analysis using Tukey correction was used in cases of statistically significant results in ANOVA tests. Following this, a multivariate analysis was carried out (as multiple logistic regression models) to predict the study outcomes, which were used to control for possible confounding between $\mathrm{CD}$ and other covariates. The choice of covariates in the models was based on the significance level in the bivariate analysis, i.e., all covariates that showed a significant association with the outcome were included in the model.

\section{Ethical considerations}

Ethical considerations were followed according to the Declaration of Helsinki. Approval to execute the study was obtained from the Research Ethics Committee at King Abdulaziz University (KAU) (number 078-09-17). Also, parents had to sign a parental consent form for the participation of their child.

\section{Results}

This case-control study comprised 208 children, aged 6-14 years, divided equally into 104 patients in the case group and 104 healthy children in the control group, all of which satisfied the inclusion and exclusion criteria.

\section{Baseline characteristics of the participants}

Socio-demographic data revealed a mean age of $10.67 \pm 2.39$ years for the children with $\mathrm{CD}$ and $10.69 \pm 2.36$ years for the healthy controls $(P=0.971)$. In both the $C D$ and control groups, $50 \%$ of participants were girls. Comparing the $\mathrm{CD}$ patients and control groups, there were no statistically significant differences between the two groups in terms of gender $(P=1.00)$, age categories $(P=0.980)$, family income $(P=0.874)$, mother education $(P=0.052)$, and father education $(P=0.781)$.

The oral hygiene and dietary habits of the participants are shown in Table 1. The proportion of children with CD that habitually took part in daily tooth brushing was significantly higher than the proportion of the control group (60.6\% vs. $46.2 \% ; P=0.037)$. There were no statistically significant differences between $C D$ patients and the controls in terms of frequency of tooth brushing $(P=0.535)$, getting help with brushing $(P=0.889)$, swallowing toothpaste $(P=0.42)$, water source $(P=0.249)$, use of Zamzam holy water $(P=0.507)$, consumption of sweets $(P=0.323)$, intake of carbohydrates $(P=0.308)$, and daily intake of soft drinks $(P=0.369)$.

\section{Oral health status among participants}

In this study, RAS was found in $42.3 \%$ of CD children and $15.4 \%$ of the controls $(P<0.001)$ (Fig. 1$)$. Having $C D$ significantly increased the odds of having RAS by 4.03 times the rate of the healthy controls $(95 \%, \mathrm{CI}=2.09$ 7.81). Similarly, children with $C D$ had more frequent DEDs than controls $(70.2 \%$ vs. $34.6 \%, P<0.001)$, and CD children were 4.45 times more likely to have DEDs than healthy controls $(95 \%, \mathrm{CI}=2.48-7.97)$. Figure $2 \mathrm{a}-\mathrm{f}$ represents the different forms of DEDs that were recognized in the study. Furthermore, children with $C D$ were less likely to have DEDs Grade $0(\mathrm{OR}=0.27)$ but more likely to have DEDs Grade I $(\mathrm{OR}=3.39)$ than controls. Dental caries was evaluated as caries prevalence, using the combined caries experience for both primary and permanent teeth combined (DMFT/dmft), as a dichotomous variable $(\mathrm{DMFT} / \mathrm{dmft}>0$ or $\mathrm{DMFT} / \mathrm{dmft}=0)$. When there is no caries experience in primary or permanent teeth, the score is equal to zero; caries severity is evaluated using the continuous variable of decayed, missed, and filled index for permanent and primary 
Table 1 Oral hygiene and dietary habits among the study groups

Celiac $\mathrm{N}=104 \quad$ Control $\mathrm{N}=104 \quad P$ value

n (\%)

\begin{tabular}{|c|c|c|c|}
\hline \multicolumn{4}{|l|}{ Brushing teeth } \\
\hline Yes & $63(60.6)$ & $48(46.2)$ & \multirow[t]{2}{*}{$0.037^{* \dagger}$} \\
\hline No & $41(39.4)$ & $56(53.8)$ & \\
\hline \multicolumn{4}{|l|}{ Daily tooth brushing ${ }^{\#}$} \\
\hline Once daily & $23(36.5)$ & $18(37.5)$ & \multirow[t]{2}{*}{$0.535^{\dagger}$} \\
\hline More than once daily & $40(63.5)$ & $30(62.5)$ & \\
\hline \multicolumn{4}{|l|}{ Who brushes teeth ${ }^{\#}$} \\
\hline Child & $45(43.3)$ & $46(44.2)$ & \multirow[t]{2}{*}{$0.889^{\ddagger}$} \\
\hline Adult involved & $18(17.3)$ & $2(1.9)$ & \\
\hline \multicolumn{4}{|c|}{ Swallow toothpaste (0-6 years) } \\
\hline Yes & $6(5.8)$ & $9(8.7)$ & \multirow[t]{2}{*}{$0.421^{\dagger}$} \\
\hline No & $98(94.2)$ & $95(91.3)$ & \\
\hline \multicolumn{4}{|l|}{ Water source (0-6 years) } \\
\hline Bottle & $85(81.7)$ & $91(87.5)$ & \multirow[t]{2}{*}{$0.249^{\dagger}$} \\
\hline Tap & $19(18.3)$ & $13(12.5)$ & \\
\hline \multicolumn{4}{|l|}{ Zamzam ( $0-6$ years) } \\
\hline Yes & $13(12.5)$ & $10(9.6)$ & \multirow[t]{2}{*}{$0.507^{\dagger}$} \\
\hline No & $91(87.5)$ & $94(90.4)$ & \\
\hline \multicolumn{4}{|l|}{ Sweets daily intake } \\
\hline$<3$ times & $80(76.9)$ & 74 (71.2) & \multirow[t]{2}{*}{$0.343^{\dagger}$} \\
\hline$\geq 3$ times & $24(23.1)$ & $30(28.8)$ & \\
\hline \multicolumn{4}{|l|}{ Soft drinks daily intake } \\
\hline$<3$ times & $100(96.2)$ & $103(99.0)$ & \multirow[t]{2}{*}{$0.369^{\ddagger}$} \\
\hline$\geq 3$ times & $4(3.8)$ & $1(1.0)$ & \\
\hline \multicolumn{4}{|l|}{ Carbohydrate daily intake } \\
\hline Yes & $79(76.0)$ & $85(81.7)$ & \multirow[t]{2}{*}{$0.308^{\dagger}$} \\
\hline No & $25(24.0)$ & 19 (18.3) & \\
\hline
\end{tabular}

Bold values indicate significant levels of $P$ values

$N$ total number of participants, $n$ number of participants in each group

\# Total number of those who brushed their teeth from the total N. Does not brush was not included in this analysis

${ }^{\dagger}$ Chi-squared test

* Fisher's exact test was used when the number of participants is less than 5

${ }^{*} P<0.05$, using a chi-squared test

teeth (DMFT/dmft). There was no statistically significant difference found between CD cases and controls in the frequency of malocclusion of various severities (Table 2).

Dental caries experience among the study participants are shown in Table 3. Children with CD were less likely to have experienced dental caries than healthy controls. In terms of the $\mathrm{dmft}$ of the primary dentition, the mean $\mathrm{dmft}$ in children with $\mathrm{CD}(5.01 \pm 4.0)$ was significantly lower than healthy controls $(6.56 \pm 4.20) \quad(P=0.019)$. Also, the mean number of decayed teeth in children with

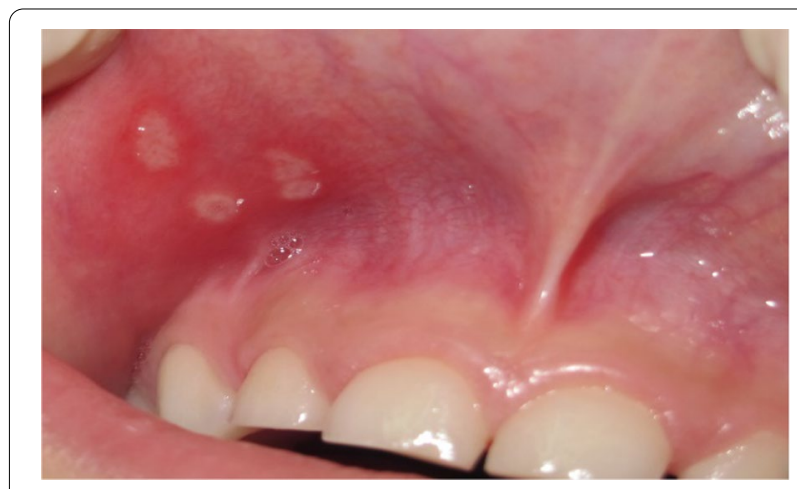

Fig. 1 RAS. Three ulcerations of variable sizes in the maxillary labial mucosa of a 7-year-old girl with CD

CD was significantly lower $(3.70 \pm 3.65)$ than healthy controls $(5.13 \pm 3.86)(P=0.018)$. When considering the dental caries in the permanent dentition, DMFT showed no significant difference between the two groups $(P=0.200)$, but the mean number of decayed permanent teeth in children with CD $(2.81 \pm 3.21)$ was significantly higher than healthy controls $(1.90 \pm 2.18)(P=0.021)$. Furthermore, when the dental caries consequences were analyzed as a continuous variable, the mean pufa in primary teeth was statistically lower in the CD group $(1.44 \pm 2.14)$ compared to the control group $(2.66 \pm 3.10)(P=0.004)$. When the dental caries consequences were analyzed as a continuous variable, the pulpal consequences were significantly lower in children with CD $(1.59 \pm 2.05)$ than healthy controls $(2.84 \pm 3.19)(P=0.005)$. Also, the pulpal consequences were significantly lower in children with $\mathrm{CD}(1.33 \pm 1.93)$ than healthy controls $(2.67 \pm 3.11)$ $(P=0.001)$. The mean PUFA in permanent teeth was not statistically different between the two groups $(P=0.096)$ but the pulpal consequences were significantly higher in children with $\mathrm{CD}(0.46 \pm 1.02)$ than healthy controls $(0.22 \pm 0.53)(P=0.044)$.

\section{Effect of CD on development of RAS, DEDs, and dental caries after adjustment for teeth brushing}

Three multiple logistic regressions were used to evaluate the effects of CD on RAS, DED, and dental caries, controlling for teeth brushing. Children with $\mathrm{CD}$ had 3.79 times more likely of having RAS (95\%, CI 1.96-7.35) compared to children without $\mathrm{CD}(P<0.001)$. Also, the CD group were 4.39 times more likely to have DEDs (95\% CI, 2.44-7.89) than controls. CD was not shown to be a significant predictor of dental caries $(P=0.235)$ in this model (Table 4). 


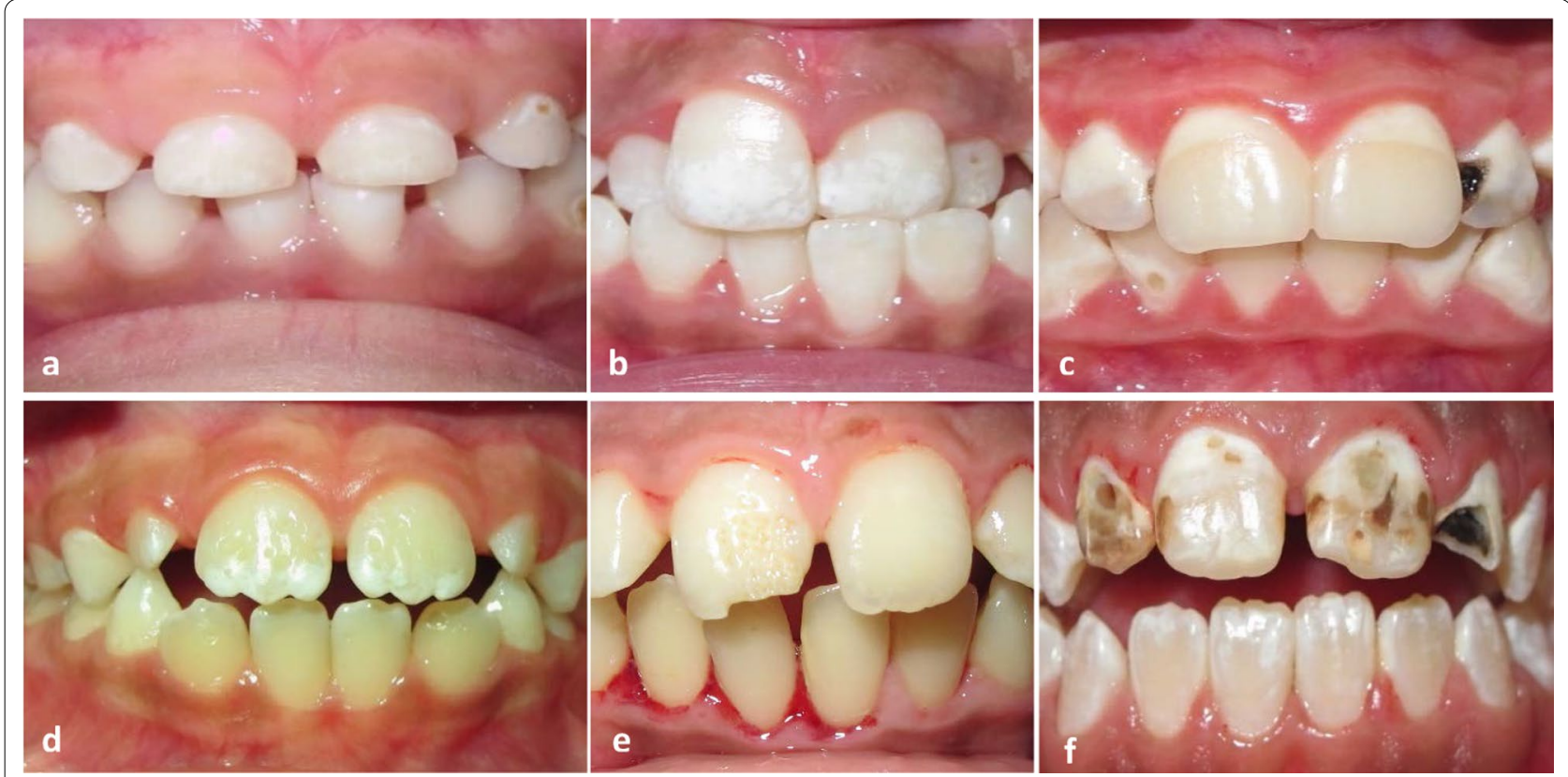

Fig. 2 DEDs in Patients with CD. Grade I (enamel color defect): white diffuse opacities in upper incisors in primary teeth in a 7-year-old boy (a). Grade I (enamel color defect): white diffuse opacities in upper anterior teeth in a 10-year-old boy (b). Grade I (enamel color defect): clearly defined white opacities in a 13-year-old girl (c). Grade II (mild structural defect) shallow pits in upper central incisors in a 6.5-year-old girl (d). Grade III (evident structural defect): large vertical pits in a 12-year-old boy with CD (e). Grade III (evident structural defect): generalized large opacities of different colors, also an open bite exists in a 12-year-old girl ( $\mathbf{f}$ )

\section{Discussion}

Celiac disease (CD) is an autoimmune enteropathy affecting the small intestine in which the ingestion of gluten, possibly with other environmental factors, trigger damage to the intestinal villi, often leading to atrophy [1]. Oral manifestations of CD have been the focus of numerous studies. Generally, studies report on a single manifestation or multiple oral manifestations [3, $4,7-9,15,22]$. In the present study, CD increased the likelihood of having RAS by about 4.03 times healthy controls, in agreement with one previous study, which reported a similar odds ratio $(\mathrm{OR}=4.12)$ [23]. Several studies also reported a greater occurrence of RAS in children with CD than healthy controls $[11,12,15,24$, 25]. Only one case-control study, using a smaller sample size, failed to show an association [7]. We found also that DEDs are more prevalent in children with $\mathrm{CD}$ than healthy controls, where children with $\mathrm{CD}$ had a greater prevalence of DEDs, supporting some previously reported studies [7, 11, 12, 15, 24, 25]. Conversely, one study reported no difference in the prevalence of DEDs in CD children and controls [23].

DEDs occur during the period of teeth formation when exposure to gluten may play a role in development [12]. Gluten triggers the production of antibodies against the enamel proteins, presumably causing DEDs, either in primary or permanent teeth. These antibodies may pass through the placental blood barrier during tooth formation [26]. Thus, early diagnosis of $\mathrm{CD}$ at a younger age and the institution of a gluten-free diet (GFD) may prevent the development of DEDs in permanent teeth [26, 27].

Several reports of the association of dental caries in children with $C D$ have shown inconsistent results $[7$, 10-14]. Our study showed that children with CD had a lower caries experience and had a lower likelihood of experiencing caries than healthy controls. This finding is supported by one study that found that dental caries in permanent teeth in a CD group was lower than controls [13]. In our study, dental caries experience was measured using DMFT/dmft scores. In primary teeth, the scores were significantly lower in the $\mathrm{CD}$ group than healthy controls. However, in permanent teeth, children with CD showed a significantly higher number of decayed teeth than did healthy controls. These two results correspond with a previous study which showed that in permanent teeth there were substantially higher mean DMFT scores in children with $\mathrm{CD}$ than controls. In contrast, in primary teeth, children with $\mathrm{CD}$ had lower mean $\mathrm{dmft}$ scores than controls, but this was statistically insignificant [24]. It should also be noted that some previous studies documented a statistically insignificant difference between 
Table 2 Oral health status among the CD and control groups (percentage distribution)

\begin{tabular}{|c|c|c|c|c|}
\hline Variables & $\begin{array}{l}\text { Celiac N=104 } \\
n(\%)\end{array}$ & Control $N=104$ & $P$ value & OR $(95 \% \mathrm{Cl})$ \\
\hline \multicolumn{5}{|l|}{ RAS } \\
\hline Yes & $44(42.3)$ & $16(15.4)$ & $<0.001^{* \dagger}$ & $4.03(2.09-7.81)$ \\
\hline No & $60(57.7)$ & $88(84.6)$ & & Ref \\
\hline \multicolumn{5}{|l|}{ DED } \\
\hline Yes & $73(70.2)$ & $36(34.6)$ & $<0.001 *^{\dagger}$ & $4.45(2.48-7.97)$ \\
\hline No & $31(29.8)$ & $68(65.4)$ & & Ref \\
\hline DED Grade I & $51(49.0)$ & $23(22.1)$ & $<0.001^{* * \neq}$ & $3.39(1.86-6.19)$ \\
\hline DED Grade II & $18(17.3)$ & $11(10.6)$ & & $1.77(0.79-3.60)$ \\
\hline DED > Grade II & $4(3.8)$ & $2(1.9)$ & & $2.04(0.37-11.39)$ \\
\hline \multicolumn{5}{|l|}{ Dental caries experience } \\
\hline Yes & $89(85.6 \%)$ & $98(94.2 \%)$ & $0.038^{*^{\dagger}}$ & $0.36(0.14-0.98)$ \\
\hline No & $15(14.4 \%)$ & $6(5.8 \%)$ & & Ref \\
\hline \multicolumn{5}{|l|}{ Malocclusion*** } \\
\hline No/mild & $21(21.4 \%)$ & $23(23.5 \%)$ & $0.732^{\dagger}$ & $0.89(0.45-1.74)$ \\
\hline Defined & $28(28.6 \%)$ & $29(29.6 \%)$ & $0.875^{\dagger}$ & $0.95(0.51-1.76)$ \\
\hline Severe & $24(24.5 \%)$ & $21(21.4 \%)$ & $0.610^{\dagger}$ & $1.19(0.61-2.32)$ \\
\hline Very severe & $25(25.5 \%)$ & $25(25.5 \%)$ & $1.00^{\dagger}$ & $1.00(0.53-1.90)$ \\
\hline Deep bite & $13(13.3 \%)$ & $13(13.3 \%)$ & $1.00^{+}$ & $1.00(0.44-2.28)$ \\
\hline Posterior cross bite & $13(13.3 \%)$ & $8(8.2 \%)$ & $0.248^{\dagger}$ & $1.72(0.68-4.36)$ \\
\hline
\end{tabular}

Bold values indicate significant levels of $P$ values/OR $(95 \% \mathrm{Cl})$

$N$ total number of participants, $n$ number of participants in each group, $C D$ celiac disease, OR odds ratio, DED Grade / defect in enamel color, such as cream or brown opacity, well defined or diffused, Grade II slight defect in enamel structure as "horizontal grooves or shallow pits.", Grade III evident defect in enamel structure as "deep horizontal grooves or large opacities of different colors.", Grade IV severe form of defect in enamel structure as "the shape of the tooth is altered, with pointed cusps.", DMFT/dmft decayed, missed, filled permanent/primary teeth

${ }^{\dagger}$ Chi-squared test

${ }^{\ddagger}$ Fisher's exact test was used when the number of participants is less than 5

${ }^{*} P$ value $<0.05$ using chi-squared test

**P value $<0.05$ using Fisher's exact test

**Patients with only primary teeth were not assessed

children with $\mathrm{CD}$ and healthy controls for mean caries scores $[7,11,25]$.

Perhaps the increased severity of decayed permanent teeth in the current study is related to DEDs that affect tooth structure, the lower calcium to phosphorus ratio, or the decreased salivary flow, resulting in more straightforward dissolution in CD patients [12].

Our study found that dental caries experience as well as decayed primary teeth were lower in children with $\mathrm{CD}$, which may be due to good adherence to a GFD, although adherence to a GFD was not assessed in the present study. Another study found that CD children, who were compliant with a GFD, had a lower number of caries than both those that were less compliant and controls [13], which may serve to underscore the importance of implementation of a GFD. A GFD could explain the reduced dental caries in primary teeth in $C D$ patients, because of the early exclusion of a cariogenic foods, such as grains and sweets. It is important to be cognizant of the fact that dental caries is a multifactorial condition that may concern enamel and salivary composition, including reduced flow rate, dietary factors, and oral hygiene.

In this study, to assess the caries experience, the DMFT/dmft and the PUFA/pufa indices were used, assessing diseases occurring pulpo-periapically, which could result from untreated dental caries. This index may help to understand the complete picture of caries present in an individual [19].

We did not find any difference in the occurrence of malocclusion between children with $\mathrm{CD}$ and healthy controls. This finding contradicts one previous study that reported a higher rate of malocclusion in $C D$ patients than in healthy controls [28]. However, several factors may contribute to the development of malocclusion, including delayed dental eruption and mandibular growth [29]. 
Table 3 Oral health conditions among the CD and control groups (mean \pm SD)

\begin{tabular}{|c|c|c|c|}
\hline \multirow[t]{2}{*}{ Variables } & Celiac $\mathrm{N}=104$ & Control $\mathrm{N}=104$ & $P$ value $^{\dagger}$ \\
\hline & \multicolumn{3}{|l|}{ Mean \pm SD $(95 \% \mathrm{Cl})$} \\
\hline \multicolumn{4}{|c|}{ Caries experience including primary and permanent teeth } \\
\hline Decayed & $5.43 \pm 1.05(4.65-6.22)$ & $5.78 \pm 4.29(4.95-6.61)$ & 0.550 \\
\hline Missed & $0.70 \pm 1.71(0.31-1.09)$ & $0.34 \pm 0.80(0.15-0.52)$ & 0.103 \\
\hline \multirow[t]{2}{*}{ Filled } & $0.96 \pm 1.83(0.54-1.38)$ & $1.43 \pm 2.22(0.92-1.95)$ & 0.157 \\
\hline & $\mathrm{n}=\mathbf{8 1}$ & $\mathrm{n}=79$ & \\
\hline \multicolumn{4}{|c|}{ Caries experience dmft (primary teeth only) } \\
\hline Decayed primary & $3.70 \pm 3.65(2.92-4.52)$ & $5.13 \pm 3.86(4.12-5.96)$ & $0.018^{*}$ \\
\hline Missing primary & $0.64 \pm 1.67(0.30-1.09)$ & $0.30 \pm 0.72(0.13-0.47)$ & 0.098 \\
\hline Filled primary & $0.67 \pm 1.49(0.37-1.07)$ & $1.13 \pm 1.85(0.63-1.39)$ & 0.085 \\
\hline \multirow[t]{2}{*}{ Primary dmft } & $5.01 \pm 4.05(4.23-6.03)$ & $6.56 \pm 4.20(5.42-7.29)$ & $0.019 *$ \\
\hline & $n=98$ & $\mathrm{n}=98$ & \\
\hline \multicolumn{4}{|c|}{ Caries experience DMFT (permanent teeth only) } \\
\hline Decayed permanent & $2.81 \pm 3.21(2.14-3.42)$ & $1.90 \pm 2.18(1.46-2.34)$ & $0.021 *$ \\
\hline Missing permanent & $0.05 \pm 0.22(0.01-0.09)$ & $0.06 \pm 0.24(0.01-0.11)$ & 0.758 \\
\hline Filled permanent & $0.34 \pm 1.19(0.10-0.57)$ & $0.62 \pm 1.62(0.30-0.95)$ & 0.162 \\
\hline Permanent DMFT & $3.20 \pm 3.54(2.49-3.91)$ & $2.62 \pm 2.75(2.07-3.17)$ & 0.200 \\
\hline \multicolumn{4}{|c|}{ Caries consequences in primary and permanent teeth } \\
\hline Pulpal & $1.59 \pm 2.05(1.12-2.06)$ & $2.84 \pm 3.19(2.10-3.58)$ & $0.005^{*}$ \\
\hline Ulceration & $0(0.00)$ & $0(0.00)$ & - \\
\hline Fistula & $0.03 \pm 0.16(-0.01-0.06)$ & $0.04 \pm 0.26(-0.02-0.10)$ & 0.686 \\
\hline \multirow[t]{2}{*}{ Abscess } & $0.08 \pm 0.32(0.01-0.15)$ & $0.11 \pm 0.31(0.04-0.18)$ & 0.571 \\
\hline & $\mathrm{n}=\mathbf{8 1}$ & $n=79$ & \\
\hline \multicolumn{4}{|c|}{ Caries consequences pufa (primary teeth only) } \\
\hline Pulpal primary & $1.33 \pm 1.93(0.92-1.80)$ & $2.67 \pm 3.11(1.95-3.42)$ & $0.001 *$ \\
\hline Ulceration primary & $0(0.00)$ & $0(0.00)$ & - \\
\hline Fistula primary & $0.02 \pm 0.15(-0.01-0.06)$ & $0.04 \pm 0.25(-0.02-0.10)$ & 0.687 \\
\hline Abscess primary & $0.09 \pm 0.32(0.01-0.16)$ & $0.08 \pm 0.27(0.02-0.15)$ & 0.824 \\
\hline \multirow[t]{2}{*}{ Primary pufa total } & $1.44 \pm 2.14(0.98-1.95)$ & $2.66 \pm 3.10(1.94-3.41)$ & $0.004^{*}$ \\
\hline & $\mathrm{n}=98$ & $\mathrm{n}=98$ & \\
\hline \multicolumn{4}{|c|}{ Caries consequences PUFA (permanent teeth only) } \\
\hline Pulpal permanent & $0.46 \pm 1.02(0.26-0.65)$ & $0.22 \pm 0.53(0.06-0.27)$ & $0.044^{*}$ \\
\hline Ulceration permanent & $0(0.00)$ & $0(0.00)$ & - \\
\hline Fistula permanent & $0.01 \pm 0.10(-0.01-0.03)$ & $0(0.00)$ & 0.319 \\
\hline Abscess permanent & $0(0.00)$ & $0.02 \pm 0.14(-0.01-0.04)$ & 0.157 \\
\hline Permanent PUFA & $0.47 \pm 1.05(0.25-0.68)$ & $0.27 \pm 0.60(0.09-0.32)$ & 0.096 \\
\hline
\end{tabular}

Bold values indicate significant levels of $P$ values

$N$ total number of participants, $n$ number of participants in each group, $C l$ confidence interval, DMFT/dmft decayed, missed, filled permanent/primary teeth, $P$ pulp, $U$ ulceration, $F$ fistula, $A$ abscess, $S D$ standard deviation

${ }^{\dagger}$ Independent t-test

${ }^{*} P<0.05$

A strength of the present study is its case-control design, which involves the presence of an adequate sample size, homogeneity of the population studied, and the combination of clinical assessment and information gathered from a validated questionnaire.
In conclusion, children with $\mathrm{CD}$ have higher odds of RAS and DEDs than healthy controls. Also, CD patients had a higher prevalence of dental caries in permanent teeth and a lower frequency in primary teeth. 
Table 4 Multiple logistic regression models to evaluate the effect of $C D$ on independent variables controlling for teeth brushing

\begin{tabular}{|c|c|c|c|}
\hline & RAS & DED & Dental caries (yes vs. no) \\
\hline & $\begin{array}{l}\text { OR }(95 \% \mathrm{Cl}) \\
P \text { value }\end{array}$ & $\begin{array}{l}\text { OR }(95 \% \mathrm{Cl}) \\
P \text { value }\end{array}$ & $\begin{array}{l}\text { OR }(95 \% \mathrm{Cl}) \\
P \text { value }\end{array}$ \\
\hline Celiac c & isease & & \\
\hline Yes & $\begin{array}{l}3.79(1.96-7.35) \\
\boldsymbol{P}<\mathbf{0 . 0 0 1 *}\end{array}$ & $\begin{array}{l}4.39(2.44-7.89) \\
\boldsymbol{P}<\mathbf{0 . 0 0 1 *}\end{array}$ & $\begin{array}{l}0.55(0.21-1.47) \\
P=0.235\end{array}$ \\
\hline No & Reference & Reference & Reference \\
\hline Brushin & $g$ teeth & & \\
\hline Yes & $\begin{array}{l}0.74(0.39-1.40) \\
P=0.350\end{array}$ & $\begin{array}{l}1.11(0.62-2.00) \\
P=0.726\end{array}$ & $\begin{array}{l}0.18(0.05-0.63) \\
\boldsymbol{P}=\mathbf{0 . 0 0 7}^{*}\end{array}$ \\
\hline No & Reference & Reference & Reference \\
\hline
\end{tabular}

Bold values indicate statistically significant $P$ values

${ }^{*} P<0.05$

$R A S$ recurrent aphthous stomatitis, DED dental enamel defects, $O R$ odds ratio; dependent variable $=C D$; independent variables $=R A S, D E D$ s and dental caries

\begin{abstract}
Abbreviations
ASA: American Society of Anesthesiologists; CD: Celiac disease; Cl: Confidence interval; DAl: Dental aesthetic index; DEDs: Dental enamel defects; DMFT/dmft: Decayed missed and filled permanent or primary teeth; ESPGHAN: European Society of Pediatric Gastroenterology, Hepatology and Nutrition; GFD: Glutenfree diet; ICC: Intraclass correlation; I-CVI: Content validity index for item(s); KAU: King Abdulaziz University; KAUDH: King Abdulaziz University Dental Hospital; KAUH: King Abdulaziz University Hospital; OR: Odds ratio; PUFA: Pulp, ulceration, fistula or Abscess (an index of clinical consequences of untreated caries); RAS: Recurrent aphthous stomatitis; S-CVI: Content validity index for scale(s); STROBE: Strengthening The Reporting of Observational Studies in Epidemiology.
\end{abstract}

\section{Acknowledgements}

This article has been developed from part of a PhD thesis by Farah Alsadat, which was completed at King Abdulaziz University, Jeddah, in the Faculty of Dentistry. The project was funded by the Deanship of Scientific Research (DSR) at King Abdulaziz University, under grant no. G-17-165-1441. The authors wish to thank Mohammed Abdullatif Alsadat for his writing assistance. Also, the authors would like to acknowledge Dr. Trevor Rawbone, in Cardiff, UK, for English editing and proofreading of the manuscript.

\section{Authors' contributions}

FAS, OIS, AAE, NMA, conceived the ideas; FMD assisted in planning; FAS collected the data; FAS, OMF, OIS analyzed and interpreted the data, FAS, OIS, $A A E, O M F$, and NMA led the writing; $A A E, O I S$ and FMD critically revised and edited the manuscript. All authors read and approved the final manuscript.

\section{Funding}

The project was funded by the Deanship of Scientific Research (DSR) at King Abdulaziz University, Jeddah, under grant no. G-17-165-1441.

\section{Availability of data and materials}

The datasets used and/or analyzed during the current study available from the corresponding author on reasonable request.

\section{Declarations}

Ethics approval and consent to participate

Ethical considerations were followed according to the Declaration of Helsinki throughout the research process. Approval to execute the study was obtained from the Research Ethics Committee at King Abdulaziz University (KAU) (Number 078-09-17). Also, parents had to sign a parental consent form for the participation (including photos) of their child.

\section{Consent for publication}

Not applicable.

\section{Competing interests}

The authors declare that they have no competing interest.

\section{Author details}

${ }^{1}$ Dental Department, Jubail General Hospital, Ministry of Health, P.O. Box 1275, Al Jubail 31951, Saudi Arabia. ${ }^{2}$ Pediatric Dentistry Department, Faculty of Dentistry, King Abdulaziz University, Jeddah, Saudi Arabia. ${ }^{3}$ Pediatric Dentistry Department, Faculty of Dentistry, Alexandria University, Alexandria, Egypt. ${ }^{4}$ Department of Pediatrics, Faculty of Medicine, King Abdulaziz University, Jeddah, Saudi Arabia. ${ }^{5}$ Pediatric Gastroenterology Unit, Department of Pediatrics, King Abdulaziz University Hospital, Jeddah, Saudi Arabia.

Received: 12 July 2021 Accepted: 16 November 2021

Published online: 29 December 2021

\section{References}

1. Husby S, Koletzko S, Korponay-Szabó IR, Mearin ML, Phillips A, Shamir R, et al. European Society for Pediatric Gastroenterology, hepatology, and nutrition guidelines for the diagnosis of coeliac disease. J Pediatr Gastroenterol Nutr. 2012;54(1):136-60.

2. Saadah Ol. Celiac disease in children and adolescents at a singe center in Saudi Arabia. Ann Saudi Med. 2011;31(1):51-7.

3. van Gils T, Brand HS, de Boer NK, Mulder CJ, Bouma G. Gastrointestinal diseases and their oro-dental manifestations: part 3-coeliac disease. $\mathrm{Br}$ Dent J. 2017;222(2):126-9.

4. Karlin S, Karlin E, Meiller T, Bashirelahi N. Dental and oral considerations in pediatric celiac disease. J Dent Child (Chic). 2016;83:67-70.

5. Ouda S, Saadah O, El Meligy O, Alaki S. Genetic and dental study of patients with celiac disease. J Clin Pediatr Dent. 2010;35:217-23.

6. Alamoudi NM, Alsadat FA, El-Housseiny AA, Felemban OM, Al Tuwirqi AA Mosli RH, et al. Dental maturity in children with celiac disease: a casecontrol study. BMC Oral Health. 2020;20:311

7. Cruz I-T-S-A, Fraiz F-C, Celli A, Amenabar J-M, Assunção L-R-S. Dental and oral manifestations of celiac disease. Med Oral Patol Oral Cir Bucal. 2018;23:e639-45.

8. Macho VMP, Coelho AS, Veloso E Silva DM, de Andrade DJC. Oral manifestations in pediatric patients with coeliac disease-a review article. Open Dent J. 2017;11:539-45

9. Mantegazza C, Paglia M, Angiero F, Crippa R. Oral manifestations of gastrointestinal diseases in children. Part 4: coeliac disease. Eur J Paediatr Dent. 2016:17:332-4.

10. Bramanti E, Cicciù M, Matacena $G$, Costa $S$, Magazzù G. Clinical evaluation of specific oral manifestations in pediatric patients with ascertained versus potential coeliac disease: a cross-sectional study. Gastroenterol Res Pract. 2014:2014:1-9.

11. Acar S, Yetkıner AA, Ersın N, Oncag O, Aydogdu S, Arıkan C. Oral findings and salivary parameters in children with celiac disease: a preliminary study. Med Princ Pract. 2012;21:129-33.

12. Carvalho FK, Queiroz AM, Silva RAB. Oral aspects in celiac disease children: clinical and dental enamel chemical evaluation. Oral Surg Oral Med Oral Pathol Oral Radiol. 2015;119:636-43.

13. Avşar A, Kalayci AG. The presence and distribution of dental ename defects and caries in children with celiac disease. Turk J Pediatr. 2008;50:45-50

14. Maloney WJ, Raymond G, Hershkowitz D, Rochlen G. Oral and dental manifestations of celiac disease. N Y State Dent J. 2014;80:45-8.

15. Villemur Moreau L, Dicky O, Mas E, Noirrit E, Marty M, Vaysse F, et al. Oral manifestations of celiac disease in French children. Arch Pediatr. 2021:28:105-10.

16. Vandenbroucke JP, Elm E, Altman DG. Strengthening the Reporting of Observational Studies in Epidemiology (STROBE): explanation and elaboration. Epidemiology. 2007;18:805-35.

17. Aine L, Mäki M, Collin P, Keyriläinen O. Dental enamel defects in celiac disease. J Oral Pathol Med. 1990;19:241-5.

18. WHO. Oral health surveys: basic methods. 5th ed. Geneva: World Health Organization; 2013. 
19. Monse B, Heinrich-Weltzien R, Benzian H, Holmgren C, Palenstein HW. PUFA - an index of clinical consequences of untreated dental caries. Community Dent Oral Epidemiol. 2010;38:77-82.

20. Cons NC, Jenny J, Kohout FJ, Songpaisan Y, Jotikastira D. Utility of the dental aesthetic index in industrialized and developing countries. J Public Health Dent. 1989;49:163-6.

21. Polit DF, Beck CT. The content validity index: are you sure you know what's being reported? Critique and recommendations. Res Nurs Health. 2006;29:489-97.

22. Shteyer E, Berson T, Lachmanovitz O, Hidas A, Wilschanski M, Menachem $M$, et al. Oral health status and salivary properties in relation to glutenfree diet in children with celiac disease. J Pediatr Gastroenterol Nutr. 2013;57:49-52.

23. Procaccini M, Campisi G, Bufo P, Compilato D, Massaccesi C, Catassi C, et al. Lack of association between celiac disease and dental enamel hypoplasia in a case-control study from an Italian central region. Head Face Med. 2007;3:25

24. Cantekin K, Arslan D, Delikan E. Presence and distribution of dental enamel defects, recurrent aphthous lesions and dental caries in children with celiac disease. Pak J Med Sci Q. 2015;31:606-9.

25. Zoumpoulakis M, Fotoulaki M, Topitsoglou V, Lazidou P, Zouloumis L, Kotsanos N. Prevalence of dental enamel defects, aphthous-like ulcers and other oral manifestations in celiac children and adolescents: a comparative study. J Clin Pediatr Dent. 2019;43:274-80.

26. Sóñora C, Arbildi P, Rodríguez-Camejo C, Beovide V, Marco A, Hernández A. Enamel organ proteins as targets for antibodies in celiac disease: implications for oral health. Eur J Oral Sci. 2016;124:11-6.

27. Bossù M, Bartoli A, Orsini G, Luppino E, Polimeni A. Enamel hypoplasia in coeliac children: a potential clinical marker of early diagnosis. Eur J Paediatr Dent. 2007;8:31-7.

28. Abdul-Wahid SF, Al-Azawi LA, Ibrahim IT. Enamel defects and malocclusion in patients with celiac disease. J Baghdad Coll Dent. 2005;17:98-100.

29. Bilello G, Ciulla C, Caradonna C. Celiac disease and malocclusion. Recent Prog Med. 2010;101:159-62.

\section{Publisher's Note}

Springer Nature remains neutral with regard to jurisdictional claims in published maps and institutional affiliations.

Ready to submit your research? Choose BMC and benefit from:

- fast, convenient online submission

- thorough peer review by experienced researchers in your field

- rapid publication on acceptance

- support for research data, including large and complex data types

- gold Open Access which fosters wider collaboration and increased citations

- maximum visibility for your research: over $100 \mathrm{M}$ website views per year

At BMC, research is always in progress.

Learn more biomedcentral.com/submissions 